\title{
Eltrombopag and its iron chelating properties in pediatric acute myeloid leukemia
}

\author{
Maura Argenziano ${ }^{1}$, Chiara Tortora ${ }^{1}$, Alessandra Di Paola ${ }^{2}$, Elvira Pota ${ }^{1}$, Martina Di \\ Martino ${ }^{1}$, Daniela Di Pinto ${ }^{1}$, Caterina Di Leva ${ }^{1}$ and Francesca Rossi ${ }^{1}$ \\ ${ }^{1}$ Department of Woman, Child and General and Specialist Surgery, University of Campania Luigi Vanvitelli, Naples 80138 , \\ Italy \\ ${ }^{2}$ Department of Experimental Medicine, University of Campania Luigi Vanvitelli, Naples 80138, Italy \\ Correspondence to: Francesca Rossi, email: francescarossi@unicampania.it
}

Keywords: acute monocytic leukemia; eltrombopag; deferasirox; iron chelation; cancer

Received: May 10,2021 Accepted: June 11,2021 Published: July 06, 2021

Copyright: ( 2021 Argenziano et al. This is an open access article distributed under the terms of the Creative Commons Attribution License (CC BY 3.0), which permits unrestricted use, distribution, and reproduction in any medium, provided the original author and source are credited.

\section{ABSTRACT}

Pediatric acute myeloid leukemia (AML) represents $20 \%$ of total childhood leukemia diagnoses and is characterized by poor prognosis with a long-term survival rate around the $\mathbf{5 0} \%$, when patients are properly treated. The standard treatment for pediatric AML currently consists in a combination of cytarabine (Ara-C) and antracycline. Iron plays an important role in cancer development and progression. Targeting iron and its metabolism mediators could be a novel therapeutic strategy in cancer.Deferasirox (DFX) inhibits cancer cell proliferation and its use as an antiblastic drug could be suggested. Eltrombopag (ELT), a thrombopoietin receptor agonist used in immunethrombocytopenia, shows anticancer properties related to its emerging iron chelating properties. We compare the anticancer effect of classically used cytarabine with DFX and ELT effects in a pediatric AML cell line, THP-1, in order to identify innovative and more effective therapeutic strategies. ELT and DFX reduce intracellular iron concentration by inhibiting its uptake and by promoting its release. In particular, even though further investigations are needed to better understand the extact underlying action mechanisms, we demonstrated that ELT improves cytarabine antineoplastic activity in pediatric AML cell line.

\section{INTRODUCTION}

Acute myeloid leukemia (AML) represents the $20 \%$ of total childhood leukemia diagnoses [1], even though it remains the most frequent type of acute leukemia in the elderly [2]. In 0-2 year-old children, this kind of leukemia is characterized by poor prognosis, with a survival rate around the $60 \%$ [3], and high treatment-related toxicity [4]. In infants the most common subtype of AML is the acute monocytic leukemia (AMoL) responsible for high mortality and morbidity [5].

The combined administration of cytarabine (Ara-C) and antracycline currently represents the principal therapeutic strategy for AML in pediatric patients, while for post-remission therapy repeated courses of high-dose Ara-C together with other cytotoxic agents are strongly indicated [3]. Also allogeneic hematopoietic stem cell transplantation (HSCT) is widely utilized to consolidate the state of remission [6], even though its actual benefits in comparison to conventionally used chemotherapy has been questioned in last years since the observed risk of relapse and late side effects. Although the amelioration of outcome for this pathology [7], stronger efforts to overcome the side effects related to standard therapy and also to ameliorate the life quality of patients are needed. Nowadays the involvement of iron and its metabolism mediators in tumor onset and progression is well documented, including in AML [8]. Considering the importance of iron in both physiological and pathological cell functions, any alterations in its metabolism could be very deleterious for human health. In particular, in literature it is reported a strong correlation between iron excess and cancer onset and progression [9], since 
the great request showed from cancer cells to sustain their metabolic processes. In AML iron overload is very frequent and could be defined as "primary", due to deficit in erythropoiesis, or "secondary", related to the repeated red blood cells transfusions principally aimed to counteract anemia [10]. Anyway, this condition has been seen to worsen AML symptoms, contributing to bone marrow failure [11] and to immune response decrease [12]. Therefore, serum and cellular iron levels are valid prognostic factors in predicting patients' response to therapy or also hematopoietic stem cell transplantation outcome $[13,14]$. The altered iron metabolism in AML patients is also strongly related to a dysregulation in the expression of iron metabolism mediators at AML cells level. For example, these cells overexpress the transferrin receptor, TFRC, for the internalization of transferrin-iron complexes, thus demonstrating their high iron consumption [15-17]. On these bases, contrasting iron overload could represent an effective anticancer strategy also in AML [18, 19].

European Medicines Agency (EMA) approved three iron chelators for treatment of iron overload conditions: deferoxamine (DFO) generally used in thalassemia major, deferiprone (DFP) and deferasirox (DFX) instead indicated in leukemic patients. In particular, DFX has also anticancer properties since it limits cancer cell proliferation by inhibiting NF-kB [20] and enhances p53 transcriptional activity impairing leukemic cells growth [21, 22]. Besides these compounds, other molecules with iron chelating properties are under investigations and among them one of the most promising is Eltrombopag (ELT), a thrombopoietin receptor agonist, normally indicated for use in immunethombocytopenia (ITP) and aplastic anemia. Vlachodimitropoulou et al. demonstrated that ELT mobilizes iron from intracellular compartment, thus reducing the metal availability for cancer cell metabolic processes, and proposed a shuttling mechanism when ELT and DFX are combined. In particular, ELT decreases cellular iron and further enhances iron mobilization donating it to DFX. [23]. However, the possibility to use ELT in AML patients is controversial. In 2018 Mittelman et al. observed a lower rate of clinically relevant thrombocytopenic events in the group treated with ELT [24]. In contrast, Frey and collaborators revealed an increase in adverse events after the administration of ELT in patients [25].

In this study we tested cytarabine, the most commonly used anticancer drug in AML, with both DFX, one of the most diffused iron chelators in leukemia, and ELT, an emerging iron chelating agent, in THP-1 cell line. The purpose of our study was to investigate the possibility to combine iron chelation with standard anti-leukemic treatments, to ameliorate the therapeutic outcome for leukemic pediatric patients, contributing to improve therapy response and consequent life quality.

\section{RESULTS}

\section{Effects of treatments on viability}

We evaluated the effect of ELT, DFX and Cytarabine, alone and in combination, on THP-1 cells viability, after $48 \mathrm{~h}$ of exposure by means of a specific cytofluorimetric assay. At the chosen concentrations, ELT and DFX did not cause any alteration in cell viability, indicating they are not cytotoxic for THP-1 cells, differently from Cytarabine which, as expected being it a chemotherapy drug, caused a very strong reduction of viable cells. A similar reduction in viability is observed also after all the co-treatments. In particular, the cytotoxicity of Cytarabine is exacerbated when used in combination with ELT (Table 1).

\section{Effects of treatments on iron metabolism}

To evaluate the influence of ELT and DFX, alone and in combination, on iron metabolism of THP-1 cells, we performed Western Blotting analyzing the expression levels of two key modulators of iron metabolism: transferrin receptor 1 (TFR-1) and Ferroportin. TRF-1 is responsible for iron internalization and after 48-hour exposure to ELT and DFX its expression was reduced but only with DFX in a statistically significant manner (Figure 1A). Ferroportin is the only known iron exporter protein. We observed its decrease after DFX administration and its increase after ELT administration. This increase is even more marked when ELT and DFX are combined (Figure 1B). These results are in line with the colorimetric iron assay by means we observed a reduction of intracellular $\mathrm{Fe}^{3+}$ (ferric iron) (Figure 2A) and a contemporary increase of extracellular $\mathrm{Fe}^{2+}$ (ferrous iron) (Figure 2B), after all treatments but especially after ELT exposure.

\section{Effects of treatments on apoptosis}

After 48-hour exposure of THP1 cell line to ELT $[10 \mu \mathrm{M}]$, DFX $[10 \mu \mathrm{M}]$ and Cytarabine $[5 \mu \mathrm{M}]$, alone and in combination, we studied the effects on apoptosis by means of a cytofluorometric assay on Muse Cell Analyzer (Merk-Millipore) and by Western Blotting evaluating BAX/Bcl-2 and Caspase-3 protein expression. In particular, $\mathrm{BAX}$ protein has a pro-apoptotic role, while Bcl-2 an anti-apoptotic function. Caspase- 3 is instead one of the main effector protein of apoptosis. The increase in $\mathrm{BAX} / \mathrm{Bcl}-2$ ratio as well as in Caspase-3 expression levels indicates an anti-tumoral effect of treatment. We observed a statistically significant increase in $\mathrm{BAX} / \mathrm{Bcl}-2$ ratio only after treatment with DFX alone and ELT plus Cytarabine (Figure 3A), on the contrary Caspase-3 decreased after all the administered treatments (Figure 3B). This results only in part resemble what observed with cytofluorimetric assay (Table 2), which highlighted a statistically significant increase in apoptotic cell percentage after 


\begin{tabular}{|c|c|}
\hline & Cell Viability \% \\
\hline NT & $91,25 \pm 5,9$ \\
\hline ELT & $83,10 \pm 1,7$ \\
\hline DFX & $90,45 \pm 8,5$ \\
\hline CYT & $54,40 \pm 1,2^{*}$ \\
\hline ELT + DFX & $74,40 \pm 4,1^{*}$ \\
\hline $\mathbf{E L T}+\mathbf{C Y T}^{*}$ & $44,90 \pm 6,9^{*}$ \\
\hline DFX + CYT $^{*}$ & $60,30 \pm 2,5^{*}$ \\
\hline
\end{tabular}

The table shows the percentage of cell viability after 48-hour treatment with ELT, DFX and Cytarabine, alone and in combination. The experiment was run in triplicate and results showed as mean \pm SD. Student's $t$ test was used for statistical analysis. $p \leq 0.05$ was considered statistically significant, ${ }^{*}$ vs non-treated sample. ${ }^{*} p \leq 0,05$.

treatments with ELT and Cytarabine alone and also after all the co-treatments, even though it is evident that the expected pro-apoptotic effect of the anticancer Cytarabine is ameliorated only by ELT.

\section{Effects of treatments on cell cycle progression}

To evaluate the effects of 48 hour-treatment with ELT, DFX and Cytarabine, alone and in combination, on cell cycle progression, we performed a specific cytofluorimetric assay on the Muse Cell Analyzer and also a Western Blotting for $\mathrm{pCDK} 2$ protein expression, a key kinase in mediating cell passage from G0/G1 to S phase. Western Blotting evidenced a significant increase of its expression after all treatments (Figure 4). While only after treatment with ELT and Cytarabine in combination we observed at Muse cell analyzer an accumulation of THP-1 cells in G0/G1 phase in comparison with nontreated sample (NT), maybe not related to $\mathrm{pCDK} 2$ protein activity (Table 3 ).
A

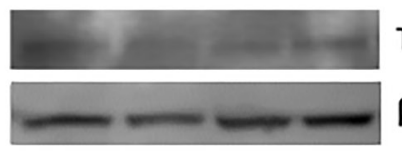

TfRI

$\beta$-Actin
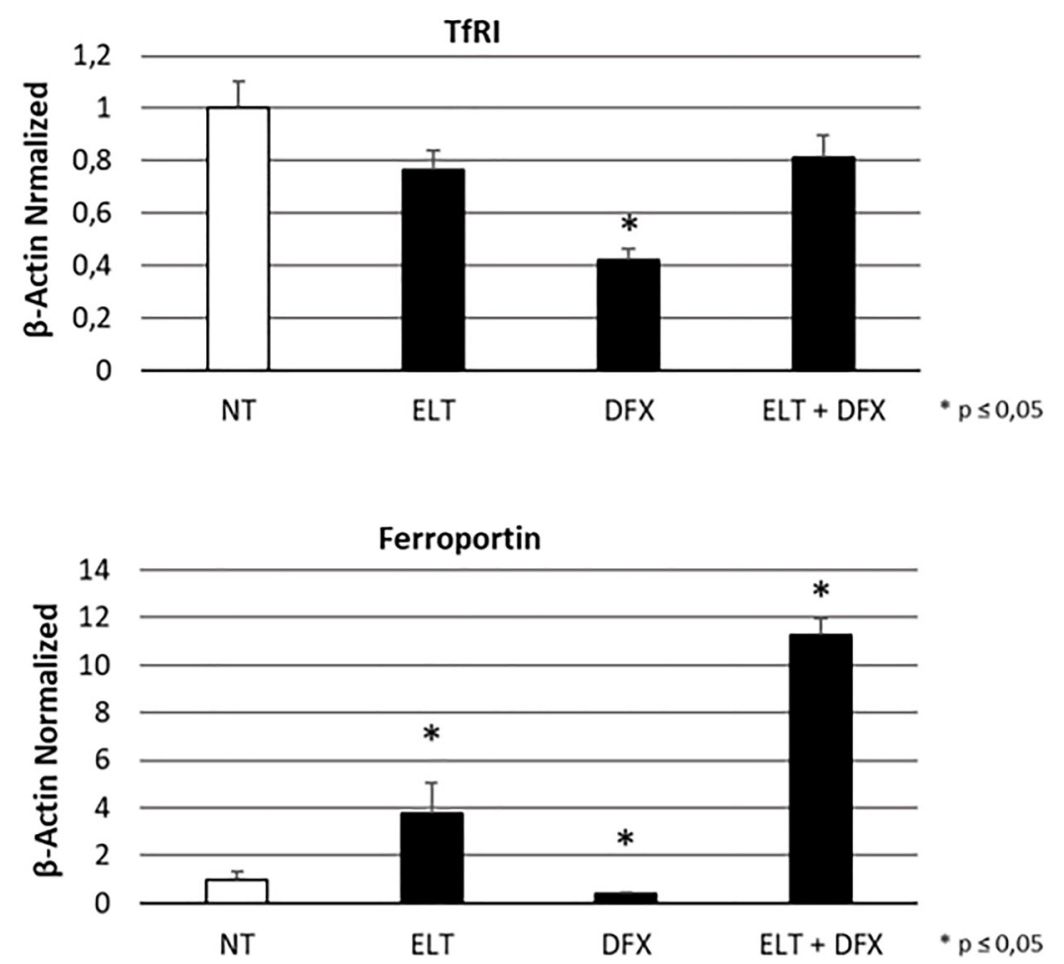

Figure 1: Effect of ELT and DFX on iron metabolism mediators. TfR1 (A) and Ferroportin (B) proteins density in THP-1 cell line was determined by Western blotting, starting from $15 \mu \mathrm{g}$ of total lysates and after $48 \mathrm{~h}$ exposure to ELT and DFX, alone and in combination. The most representative cropped images of blots are displayed. The proteins were detected using Image Studio Digits software, and the intensity of immunoblots compared to the untreated control, taken as 1 (arbitrary unit), were quantified after normalizing with respective loading controls for the housekeeping protein $\beta$-Actin. Histograms show protein expression levels as the mean \pm S.D. of three replicates. A $t$-test was used for statistical analysis. ${ }^{*}$ indicates $p \leq 0.05$ compared to non-treated sample (NT). 


\section{Effects of treatments on proliferation}

To evaluate whether ELT, DFX and Cytarabine affect THP-1 cells proliferation, we performed Western Blotting for nuclear factor kappa-light-chain-enhancer of activated B cells protein (NF-kB), strongly involved in cancer progression. All treatments reduced its expression level to more than half with a statistically significant difference with the non-treated sample (NT) (Figure 5).

A

Fe 3+

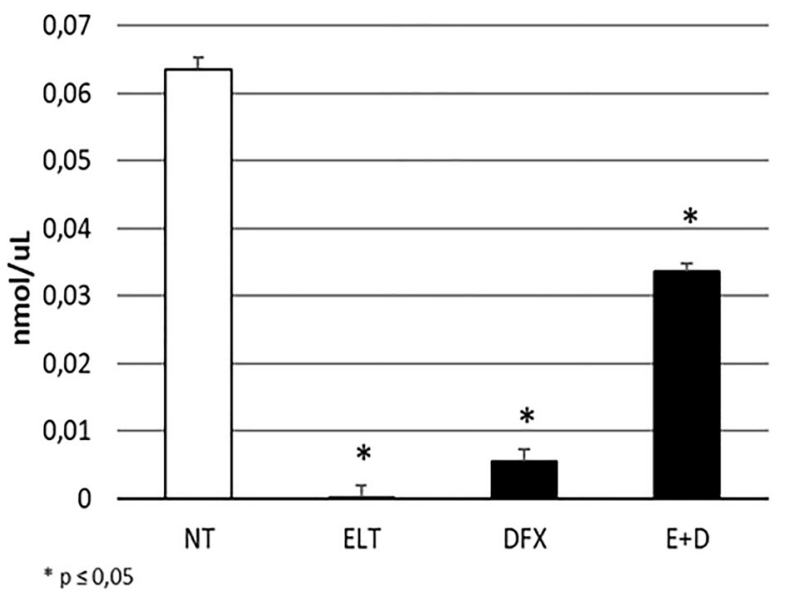

\section{DISCUSSION}

Even though acute myeloid leukemia (AML) principally affects elderly [2], it represents the $20 \%$ of childhood leukemia cases [1]. The most relevant aspect of pediatric AML remains the poor prognosis [26] with a long-term survival rate around the $50 \%$ [27], when patients are properly treated. The induction therapy combining cytarabine (Ara-C) and antracycline is nowadays the most

B

Fe $2+$

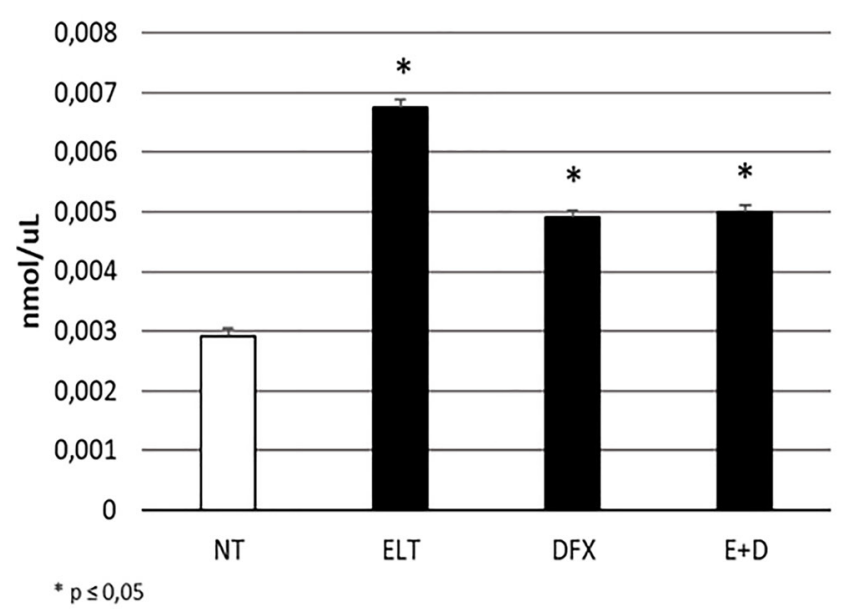

Figure 2: Effect of ELT and DFX on iron import and release. Fe3+ intracellular concentrations $(\mathrm{nmol} / \mu \mathrm{L})(\mathrm{A})$ and Fe $2+$ extracellular concentrations $(\mathrm{nmlo} / \mu \mathrm{L})(\mathbf{B})$ in THP-1 cell were determined by Iron Assay, after treatment with ELT and DFX, alone and in combination. Histograms show Fe $3+$ and Fe $2+$ concentrations as mean \pm S.D. of three independent replicate. A $t$-test was used for statistical analysis. ${ }^{*}$ indicates $p \leq 0.05$ compared to NT.

A
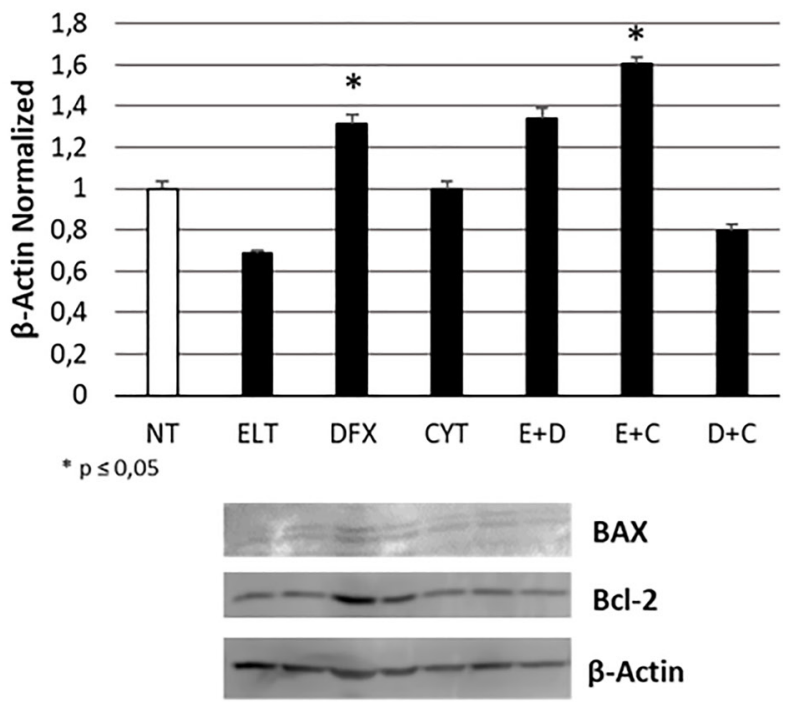

B

Caspase-3

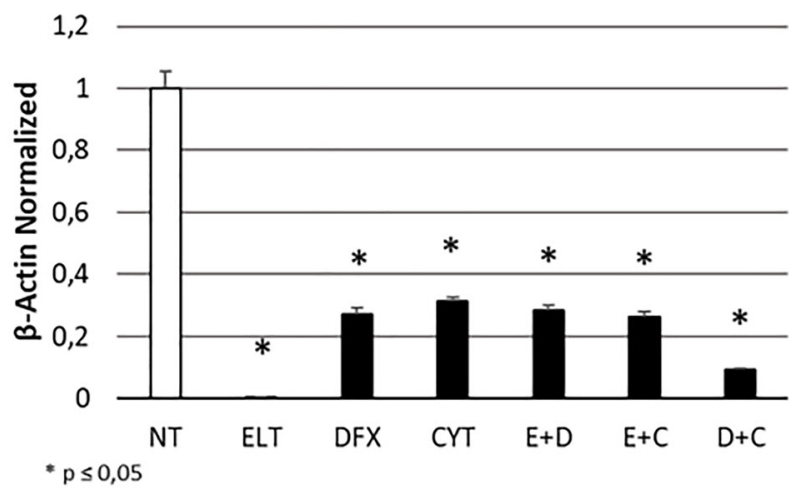

Figure 3: Effect of 48-hour treatments on apoptosis. BAX/Bcl-2 proteins ratio (A) and Caspase-3 protein (B) density in THP-1 cell line was determined by Western blotting, starting from $15 \mu \mathrm{g}$ of total lysates and after $48 \mathrm{~h}$ exposure to ELT, DFX and Cytarabine, alone and in combination. The most representative cropped images of blots are displayed. The proteins were detected using Image Studio Digits software, and the intensity of immunoblots compared to the untreated control, taken as 1 (arbitrary unit), were quantified after normalizing with respective loading controls for the housekeeping protein $\beta$-Actin. Histograms show protein expression levels as the mean \pm S.D. of three replicates. A $t$-test was used for statistical analysis. ${ }^{*}$ indicates $p \leq 0.05$ compared to non-treated sample (NT). 


\begin{tabular}{cc}
\hline \% & Total Apoptosis \\
\hline NT & $34,23 \pm 3,6$ \\
ELT & $45,98 \pm 9,9$ \\
DFX & $36,85 \pm 2,5$ \\
CYT & $66,55 \pm 5,9^{*}$ \\
ELT + DFX & $61,98 \pm 2,5$ \\
ELT + CYT & $73,50 \pm 6,7^{*}$ \\
DFX + CYT & $62,25 \pm 6,6^{*}$ \\
\hline
\end{tabular}

The table shows the percentage of total apoptosis after 48-hour treatment with ELT, DFX and Cytarabine, alone and in combination. The experiment was run in triplicate and results showed as mean $\pm \mathrm{SD}$. Student's $t$ test was used for statistical analysis. $p \leq 0.05$ was considered statistically significant, ${ }^{*}$ indicates $p \leq 0.05$ compared to non-treated sample (NT). ${ }^{*} p \leq 0,05$.

diffuse and effective therapeutic approach to treat AML pediatric patients [3]. Anyway, even though in the last years the outcome ameliorates for these patients, stronger efforts to better manage this pathology and to improve the life quality of children in long-term are needed.

In the last decade the role of iron in cancer onset and progression emerged $[28,29]$. In particular, since tumor cells show higher iron consumption than healthy cells [30], iron chelating agents represent a promising anticancer strategy. Several authors demonstrated that iron chelators inhibit proliferation and induces apoptosis in both hematological and solid tumors [21, 31]. For example, the iron chelators deferiprone (DFP) and deferasirox (DFX) are two iron chelators approved for use in leukemic patients, being able to inhibit cancer cell proliferation [20-22]. Among the innovative molecules under investigations for their emerging iron chelating properties, eltrombopag (ELT), the thrombopoietin receptor agonist used in immunethrombocytopenia (ITP) and aplastic anemia, shows anticancer properties related to its iron chelating properties [23], even though the possibility of using it is not yet concrete [24, 25, 32].

We compared the anticancer effect in THP-1 cell line of the classical chemotherapy drug, cytarabine, of DFX, the iron chelator already used in leukemic patients, and ELT, an emerging iron chelator in anticancer therapy. Moreover, we combined them with each other to investigate the possibility of a synergism between iron chelation and classical chemotherapy, in order to improve patients' response, as well as to reduce the

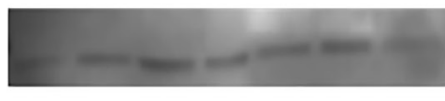

pCDK2

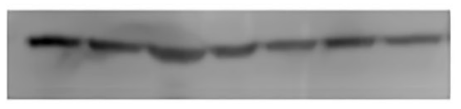

$\beta$-Actin

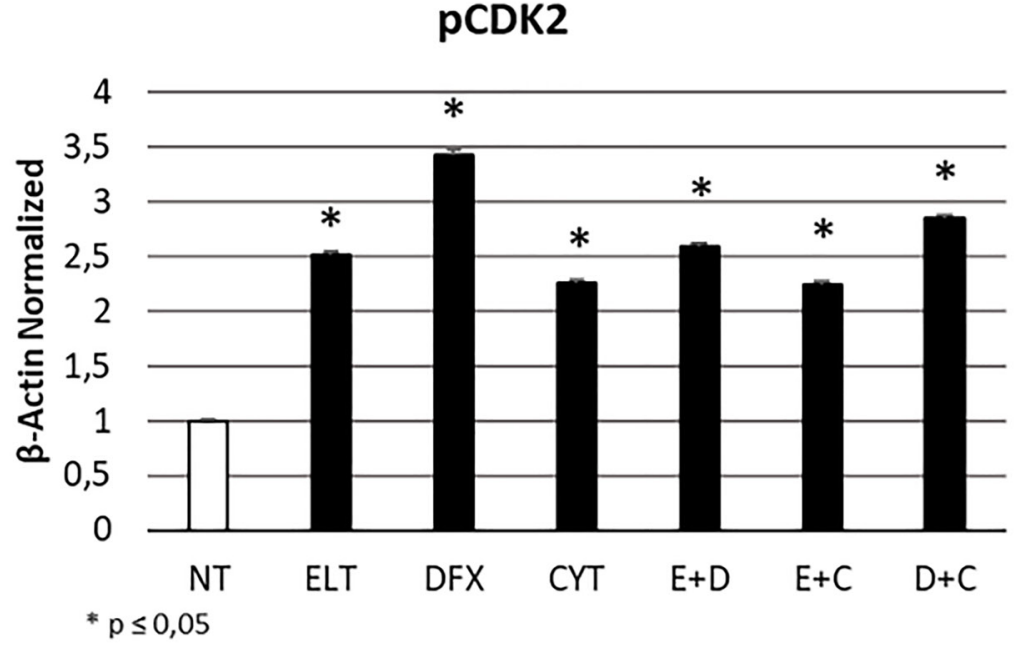

Figure 4: Effect of 48-hour treatments on cell cycle progression. pCDK2 protein expression levels in THP-1 cell line were determined by Western Blot, starting from $15 \mu \mathrm{g}$ of total lysates after $48 \mathrm{~h}$ of exposure to ELT, DFX and Cytarabine, alone and in combination. The most representative cropped images of blots are displayed. The proteins were detected using Image Studio Digit software and the intensity ratios of immunoblots compared to that of untreated control, taken as 1 (arbitrary unit), were quantified after normalizing with respective loading controls for the housekeeping protein $\beta$-Actin. The histogram represents the relative quantification for $\mathrm{pCDK} 2$ expression as mean $\pm \mathrm{SD}$ of three independent experiments A $t$-test has been used to evaluate the statistical differences in protein expression levels. ${ }^{*}$ indicates $p \leq 0.05$ compared to non-treated sample (NT). 


\begin{tabular}{lccc}
\hline \multicolumn{1}{c}{$\%$} & $\mathbf{G 0} / \mathbf{G 1}$ & $\mathbf{S}$ & $\mathbf{G} / \mathbf{M}$ \\
\hline NT & $47,6 \pm 2,7$ & $20,5 \pm 4,8$ & $28,5 \pm 4,4$ \\
ELT & $30,3 \pm 5,1^{*}$ & $29,5 \pm 0,4^{*}$ & $26 \pm 2,0$ \\
DFX & $36,75 \pm 2,0^{*}$ & $27,3 \pm 5,5^{*}$ & $31 \pm 4,5^{*}$ \\
CYT & $32 \pm 6,5^{*}$ & $48,7 \pm 7,4^{*}$ & $16,1 \pm 8,6^{*}$ \\
ELT + DFX & $33,9 \pm 6,5^{*}$ & $29,1 \pm 8,1^{*}$ & $33,3 \pm 3,4^{*}$ \\
ELT + CYT & $71,9 \pm 12,6^{*}$ & $15,6 \pm 1,2^{*}$ & $10,7 \pm 1,5^{*}$ \\
DFX + CYT & $29,5 \pm 0,8^{*}$ & $54,2 \pm 7,9^{*}$ & $14,1 \pm 1,7^{*}$ \\
\hline
\end{tabular}

Percentage of THP- 1 cell cells at different phases of the cell cycle after $48 \mathrm{~h}$ of exposure to ELT, DFX and Cytarabine, alone and in combination. Cells were harvested, fixed, incubated with Muse Cell Cycle reagents and analyzed on "MUSE Cell Analyzer". The results are presented as the mean percentage \pm SD of three independent experiments and were analyzed by $t$-test. ${ }^{*}$ indicates $p \leq 0.05$ compared to non-treated sample (NT). ${ }^{*} p \leq 0,05$.

resistance they often develop against cytarabine [33]. First of all, we confirmed the iron chelating properties of ELT and DFX also in THP-1 cell line. They indeed reduce the intracellular levels of $\mathrm{Fe} 3+$, thus making ferric iron less available for cellular vital functions. This result could be related to the observed reduction in TFR1 expression level and to the contemporary increase in Ferroportin. These proteins are the two of the principal actors in iron metabolism: TFR-1 is responsible for iron intake and Ferroportin for iron release in the extracellular microenvironment. In literature the evidences about the role of Ferroportion in cancer are discordant. Indeed, while in the major part of cancers low levels of ferroportin are related to poor prognosis [34, 35], in 2019 Gasparetto et al. observed an improved outcome to chemotherapy in
AML expressing lower levels of ferroportin [14]. This difference could be due to biological differences between cancers and also to differences in therapy strategies. Even though the role of ferroportin in cancer need to be better clarified, in literature it is clear the potential anticancer role of iron chelation and in particular ELT seems to be a very promising agent in this field $[36,37]$.

Hence, we studied the effect of treatments on cell viability, apoptosis, cell cycle progression and proliferation. First of all, we showed that cytarabine reduced cell viability and also increases apoptosis levels in THP-1 cells, as already demonstrated in other leukemia cell lines [38]. DFX and ELT instead did not affect cell viability when alone but exacerbated the effect of cytarabine, especially ELT, thus letting hypothesize
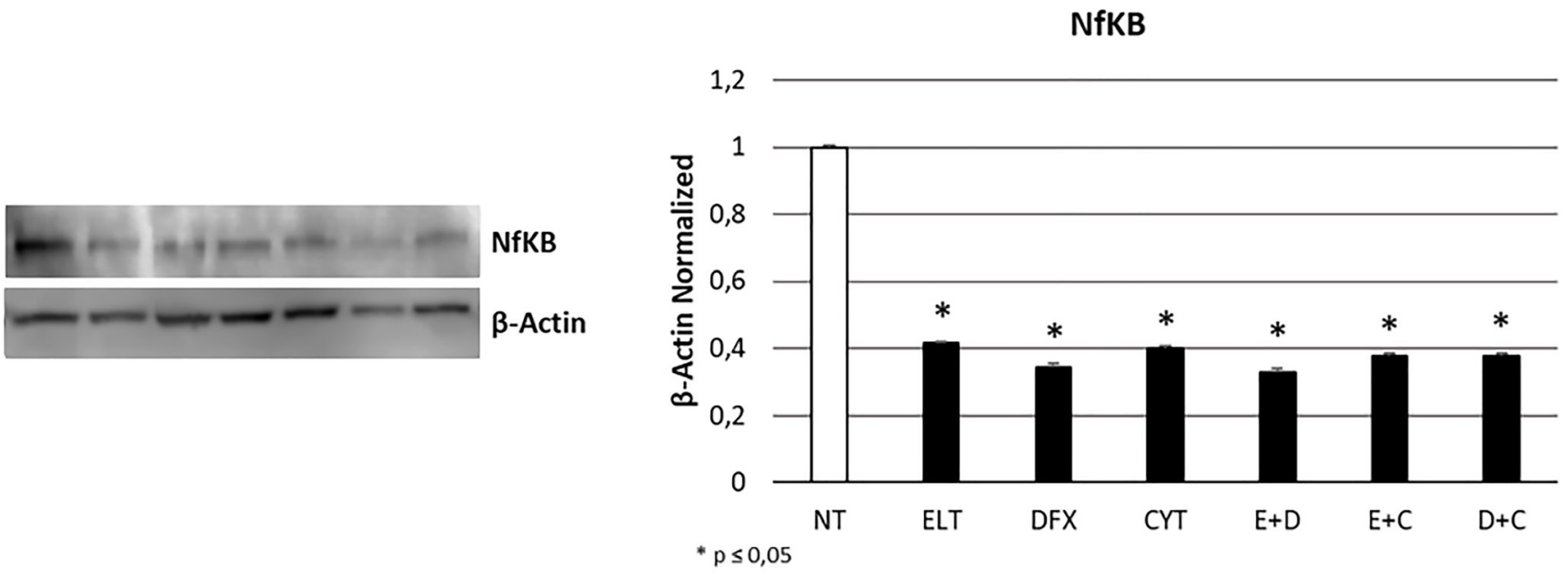

Figure 5: Effect of 48-hour treatments on proliferation. NFkB protein expression level in THP-1 cell line was determined by Western Blot, starting from $15 \mu \mathrm{g}$ of total lysates after $48 \mathrm{~h}$ of exposure to ELT, DFX and Cytarabine, alone and in combination. The most representative cropped images of blots are displayed. The proteins were detected using Image Studio Digit software and the intensity ratios of immunoblots compared to that of untreated control, taken as 1 (arbitrary unit), were quantified after normalizing with respective loading controls for the housekeeping protein $\beta$-Actin. The histogram represents the relative quantification for NFkB expression as mean $\pm \mathrm{SD}$ of three independent experiments A $t$-test has been used to evaluate the statistical differences in protein expression levels. ${ }^{*}$ indicates $p \leq 0.05$ compared to non-treated sample (NT). 
a synergism between the classical chemotherapy and the innovative anticancer drug ELT. Indeed, after cotreatment with ELT and cytarabine, cell viability reduced of almost $50 \%$, more than after each single treatment or co-treatment with DFX. ELT is able also to increase the pro-apoptotic effects of cytarabine, as demonstrated by cytofluorimetry and by the significant increase in BAX/ $\mathrm{Bcl}-2$ protein expression levels ratio. $\mathrm{Bcl}-2$ protein is normally responsible for inhibiting apoptosis and in case of resistance to cytarabine it is often up-regulated [38]. An increase in $\mathrm{BAX} / \mathrm{Bcl}-2$ ratio indicates a prevalence of the pro-apoptotic processes and interestingly in THP1 cell line this beneficial anticancer effect is evident only when cytarabine is combined with ELT. This result supports the anti-cancer effectiveness of ELT, but on the other hand it must to be better clarified considering also what reported in 2019 by Yao et al. They demonstrated how to antagonize iron-overload can instead promote Bcl2 and inhibit BAX expression, limiting the pro-apoptotic processes in healthy BMSCs [39]. This controversial aspect on iron overload management could depend on the considered cell type and health condition. As regards cell cycle progression, we observed a block in $\mathrm{S}$ phase after cytarabine administration in THP-1 cells, as also reported for decitabine, another chemotherapy drug currently used in AML not eligible for standard protocols [37]. But, when we combined it with ELT, the arrest shifted in G0/G1 phase, consistently with the already documented effects of ELT used alone $[37,40]$. Several authors demonstrated that iron chelators reduce cyclin-dependent kinase 2 (CDK2) activity [41-43], a protein normally responsible for cell cycle progression from $\mathrm{G} 0 / \mathrm{G} 1$ phase to $\mathrm{S}$ one. Deregulation in its function or expression are associated to many human cancers [44], so much that CDK2 inhibition represents a very promising anti-tumor strategy. All treatments we administered caused a significative increase in CDK2 expression, which is not in accordance with the arrest actually observed by cytofluorimetry. Therefore, it could be interesting to investigate on the hypothesis formulated by Shi et al., which observed an arrest in G0/G1 phase after treating leukemia cells with ELT and decitabine [37] and attributed this anticancer effect to the alteration in intracellular ROS levels caused by ELT [40]. We also evaluated the effect of treatments on cell proliferation by analyzing the expression levels of nuclear transcription factor-kappa beta (NFkB), one of the principal mediators of inflammation, carcinogenesis $[45,46]$ and chemotherapy resistance [38]. NFkB pathway is also involved in iron metabolism and in particular its inhibition reduces iron overload [47]. All treatments we administered in THP-1 cell line caused a significant reduction in its expression, thus mediating an important anti-proliferative effect and also a useful secondary effect of iron overload containment.

In conclusion, our study lets emerge a promising synergism between ELT and cytarabine with reduction in viability, increase in apoptosis and arrest of both proliferation and cycle progression in the pediatric AML cell line THP-1. On the other hand, we can not confirm the effectiveness of DFX in AML, neither alone neither in combination with the classically used chemotherapy agent. Further investigations are certainly needed to clarify the exact mechanisms underlying the synergism between ELT and cytarabine, in particular to understand whether ELT iron chelating properties are actually responsible for these anticancer activities. However our results encourage the possibility to combine them to increase the outcome of canonic therapeutic strategy in AML, reducing doserelated side effects associated to cytarabine as well as the chemo-resistance often developed by patients against this agent.

\section{MATERIALS AND METHODS}

\section{Leukemic cell line}

THP-1 cells are monocytes derived from 1-yearold infant affected by acute monocytic leukemia. This cell line was purchased from ATCC and cultured in suspension in RPMI-1640 Medium (Lonza, Verviers, Belgium), supplemented with $10 \%$ fetal bovine serum (FBS) (Euroclone, Siziano, Italy), $100 \mathrm{IU} / \mathrm{mL}$ penicillin, and $100 \mathrm{~g} / \mathrm{mL}$ streptomycin and L-glutamine (Gibco Limited, Uxbridge, UK). Cells were cultured at $37^{\circ} \mathrm{C}$ in a humidified atmosphere with $5 \% \mathrm{CO}_{2} .48 \mathrm{~h}$ after thawing out, cells were harvested, washed and counted on a microscope using a Burker Haemocytometer and $1,0 \times 10^{6}$ cells per well were plated in a 6 multiwell. Once $80 \%$ confluence was reached, Eltrombopag $[10 \mu \mathrm{M}]$, Deferasirox [10 $\mu \mathrm{M}]$ and Cytarabine [5 $\mu \mathrm{M}]$ were added alone and in combination. Cells were harvested at $48 \mathrm{~h}$ for Western Blotting, Iron Assay and cytofluorimetric assays to evaluate viability, apoptosis and cell cycle progression.

\section{Drugs and treatments}

ELT and DFX are two iron chelators purchased from Novartis S.p.a. (Origgio, VA, Italy). They were dissolved in sterile water at a concentration of $10 \mathrm{mM}$ for ELT and $5 \mathrm{mM}$ for DFX. Stock solutions were aliquoted and kept at $-80^{\circ} \mathrm{C}$ for long-term storage. Cytarabine is an anti-cancer drug, belonging to the antimetabolites category. Its anti-cancer effects are due to the inhibition of DNA production and repair. It is indicated for treatment of leukemia, Hodgkin's lymphoma and other types of lymphoma and it is commercialized as Cytosar-U ${ }^{\circledR}$. We diluted the initial injectable solution of $100 \mathrm{mg} / \mathrm{mL}$ to use it at the final concentration of $[5 \mu \mathrm{M}]$ in each well. THP-1 cell line was treated with ELT at the final concentration of $[10 \mu \mathrm{M}], \mathrm{DFX}$ at $[10 \mu \mathrm{M}]$ and Cytarabine at [5 $\mu \mathrm{M}]$, both alone and in all the possible combination. The used 
concentrations were determined following a pilot DoseResponse experiment (data not shown). Non-treated cultured cells were maintained in incubation media during the relative treatment time with and without a vehicle (sterile water).

\section{Protein isolation and western blot}

Proteins were extracted from treated and non-treated THP-1 cells using radio-immunoprecipitation assay (RIPA) Lysis Buffer (Millipore, Burlington, MA, USA) following the were detected in total lysates from cell line cultures by Western Blotting. Membranes were incubated overnight at $4{ }^{\circ} \mathrm{C}$ with these antibodies: goat polyclonal anti TfR1 (1:1000, Thermofisher), rabbit polyclonal anti ferroportin (1:1000, NOVUS), mouse monoclonal anti BAX (1:100, Santa Cruz), mouse monoclonal anti Bcl2 (1:200, Santa Cruz), rabbit polyclonal anti Caspase 3 (1:2000, Bethyl Laboratories, Inc.), rabbit monoclonal anti pCDK2 (1:1000, abcam), rabbit polyclonal anti NFkB (1:500, Bethyl Laboratories, Inc.). Reactive bands were detected by chemiluminescence (Immobilon Western Chemiluminescent HRP Substrate, Millipore, Burlington, MA, USA) on a C-DiGit ${ }^{\circledR}$ Blot Scanner (LI-COR Biotechnology ${ }^{\circledR}$, Lincoln, NE, USA). A mouse monoclonal anti $\beta$-Actin antibody (1:100, Santa Cruz) was used to check for comparable protein loading and as a housekeeping protein. Images were captured, stored and analyzed using "Image studio Digits ver. 5.0" software.

\section{Iron assay}

After 48 hour-treatment, cell culture supernatants were collected to measure iron (III) and iron (II). The assay was performed by using the Iron Assay Kit (Abcam, Cambridge, UK) according to the manufacturer's instructions. Briefly, standards and THP-1 cells supernatants and lysates were pipetted into the wells and were incubated with an acidic buffer to allow iron release. Then, an iron probe at $25^{\circ} \mathrm{C}$ for 60 min was added, protected from light. Released iron reacted with the chromogen resulting in a colorimetric (593 nm) product, proportional to the iron amount. The optical density was measured at a wavelength of $593 \mathrm{~nm}$ by using the Tecan Infinite M200 (Tecan Group Ltd., Männedorf, Switzerland) spectrophotometer. Iron (II) and Total Iron $(\mathrm{II}+\mathrm{III})$ contents of the test samples $(\mathrm{nmol} / \mu \mathrm{L})$ were determined against a standard concentration curve. Iron (III) content can be calculated as: Iron (III) = Total Iron (II + III) - Iron (II).

\section{Count and viability assay}

After $48 \mathrm{~h}$ exposure to ELT [10 $\mu \mathrm{M}]$, DFX [10 $\mu \mathrm{M}]$ and Cytarabine $[5 \mu \mathrm{M}]$, alone and in combination, a cytofluorimetric assay has been performed on the
Muse cell analyzer machine using the "Muse ${ }^{\circledR}$ Count and Viability Kit" according to the manufacturer's instructions. The Muse ${ }^{\circledR}$ Count \& Viability Reagent differentially stains viable and non-viable cells based on their permeability to the two DNA binding dyes present in the reagent. The two parameters considered by this assay are viability and nucleated cells. Briefly, $50 \mu \mathrm{L}$ of a cell suspension $\left(1 \times 10^{5}\right.$ cell $\left./ \mathrm{mL}\right)$ was mixed with $450 \mu \mathrm{L}$ of Muse ${ }^{\circledR}$ Count \& Viability Reagent and incubated for 5 minutes at room temperature in the dark. The results, automatically displayed, were analyzed with "Muse 1.4 Analysis" software for data acquisition and analysis.

\section{Cell dead and annexin $\mathrm{V}$ assay}

Apoptosis has been evaluated by a cytofluorimetric assay on the Muse cell analyzer machine using the "Cell dead and Annexin V Assay Kit" according to the manufacturer's instructions. Test was performed after $48 \mathrm{~h}$ of exposure to ELT [10 $\mu \mathrm{M}]$, DFX [10 $\mu \mathrm{M}]$ and Cytarabine $[5 \mu \mathrm{M}]$, alone and in combination. The Muse ${ }^{\mathrm{TM}}$ Annexin V \& Dead Cell Assay utilizes Annexin V to detect phosphatidylserine (PS) on the external membrane of apoptotic cells. A dead cell marker is also used as an indicator of cell membrane structural integrity, 7-aminoactinomycin D (7-AAD). Briefly, $100 \mu \mathrm{L}$ of a cell suspension $\left(1 \times 10^{4}\right.$ cells $\left./ \mathrm{mL}\right)$ was mixed with $100 \mu \mathrm{L}$ of Muse $^{\mathrm{TM}}$ Annexin V \& Dead Cell Reagent and incubated for $20 \mathrm{~min}$. at room temperature in dark. The results, automatically displayed, were analyzed with "Muse 1.4 Analysis" software for data acquisition.

\section{Cell cycle analysis}

Cell cycle progression was evaluated after $48 \mathrm{~h}$ exposure to ELT [10 $\mu \mathrm{M}]$, DFX [10 $\mu \mathrm{M}]$ and Cytarabine [5 $\mu \mathrm{M}]$, alone and in combination, by a cytofluorimetric assay on the Muse cell analyzer machine with the "Cell Cycle Assay Kit" according to the manufacturer's instructions. The Muse ${ }^{\mathrm{TM}}$ Cell Cycle Assay uses a propidium iodide (PI) staining of DNA content to discriminate and measure the percentage of cells in each cell cycle phase (G0/G1, S, and G2/M). The two parameters considered by this assay are cell size and DNA content. Briefly, THP-1 cells were fixed in $70 \%$ ice-cold ethanol at $4^{\circ} \mathrm{C}$ over-night, washed and incubated with Cell Cycle reagent for 30 minutes at room temperature in the dark. The results, automatically displayed, were analyzed with "Muse 1.4 Analysis" software for data acquisition.

\section{Statistical analysis}

Statistical analyses on molecular, biochemical and cellular data were performed using the Student's $t$ test (XLSTAT by Addinsoft 2020, Boston, MA, USA) to evaluate differences between quantitative variables. 
Data are expressed as mean $\pm \mathrm{SD}$ and all the experiments were run in technical triplicate. A $p$ value $\leq 0.05\left(^{*}\right)$ was considered statistically significant.

\section{Author contributions}

Argenziano M. supervision and writing of the manuscript, Tortora C. data analysis and performing experiments, Di Paola A. performing the experiments and elaboration of figures, Pota E., Di Pinto D. and Di Martino M. investigation, Di Leva C. performing the experiments, Rossi F. study design, funding acquisition, manuscript revision.

\section{CONFLICTS OF INTEREST}

Authors have no conflicts of interest to declare.

\section{FUNDING}

This research was funded by VALERE19 "InCHICAS",

\section{REFERENCES}

1. Kolb EA, Meshinchi S. Acute myeloid leukemia in children and adolescents: identification of new molecular targets brings promise of new therapies. Hematology Am Soc Hematol Educ Program. 2015; 2015:507-13. https://doi. org/10.1182/asheducation-2015.1.507. [PubMed]

2. Dou J, Li L, Guo M, Mei F, Zheng D, Xu H, Xue R, Bao $\mathrm{X}$, Zhao F, Zhang Y. Iron Oxide Nanoparticles Combined with Cytosine Arabinoside Show Anti-Leukemia Stem Cell Effects on Acute Myeloid Leukemia by Regulating Reactive Oxygen Species. Int J Nanomedicine. 2021; 16:1231-44. https://doi.org/10.2147/IJN.S278885. [PubMed]

3. Masetti R, Vendemini F, Zama D, Biagi C, Pession A, Locatelli F. Acute myeloid leukemia in infants: biology and treatment. Front Pediatr. 2015; 3:37. https://doi. org/10.3389/fped.2015.00037. [PubMed]

4. Farias MG, Freitas PAC, Spagnol F, Souza MV, Alegretti AP, Riegel M, Taniguchi ANR, Daudt LE. Hemophagocytosis by Blasts in a Child with Acute Monocytic Leukemia after Chemotherapy. Rev Paul Pediatr. 2021; 39:e2019290. https://doi.org/10.1590/1984-0462/2021/39/2019290. [PubMed]

5. Lackner H, Seidel MG, Strenger V, Sovinz P, Schwinger W, Benesch M, Sperl D, Urban C. Hemophagocytic syndrome in children with acute monoblastic leukemia-another cause of fever of unknown origin. Support Care Cancer. 2013; 21:3519-23. https://doi.org/10.1007/s00520-013-1937-x. [PubMed]

6. Egan G, Chopra Y, Mourad S, Chiang KY, Hitzler J. Treatment of acute myeloid leukemia in children:
A practical perspective. Pediatr Blood Cancer. 2021; 68:e28979. https://doi.org/10.1002/pbc.28979. [PubMed]

7. Rubnitz JE, Inaba H. Childhood acute myeloid leukaemia. Br J Haematol. 2012; 159:259-76. https://doi.org/10.1111/ bjh.12040. [PubMed]

8. Weber S, Parmon A, Kurrle N, Schnütgen F, Serve H. The Clinical Significance of Iron Overload and Iron Metabolism in Myelodysplastic Syndrome and Acute Myeloid Leukemia. Front Immunol. 2021; 11:627662. https://doi. org/10.3389/fimmu.2020.627662. [PubMed]

9. Pilo F, Angelucci E. A storm in the niche: Iron, oxidative stress and haemopoiesis. Blood Rev. 2018; 32:29-35. https://doi.org/10.1016/j.blre.2017.08.005. [PubMed]

10. Vinchi F, Hell S, Platzbecker U. Controversies on the Consequences of Iron Overload and Chelation in MDS. Hemasphere. 2020; 4:e357. https://doi.org/10.1097/ HS9.0000000000000357. [PubMed]

11. Cazzola M, Della Porta MG, Malcovati L. Clinical relevance of anemia and transfusion iron overload in myelodysplastic syndromes. Hematology Am Soc Hematol Educ Program. 2008; 2008:166-75. https://doi.org/10.1182/ asheducation-2008.1.166. [PubMed]

12. Weinberg ED. Iron loading and disease surveillance. Emerg Infect Dis. 1999; 5:346-52. https://doi.org/10.3201/ eid0503.990305. [PubMed]

13. Bertoli S, Paubelle E, Bérard E, Saland E, Thomas X, Tavitian S, Larcher MV, Vergez F, Delabesse E, Sarry A, Huguet F, Larrue C, Bosc C, et al. Ferritin heavy/light chain (FTH1/FTL) expression, serum ferritin levels, and their functional as well as prognostic roles in acute myeloid leukemia. Eur J Haematol. 2019; 102:131-42. https://doi. org/10.1111/ejh.13183. [PubMed]

14. Gasparetto M, Pei S, Minhajuddin M, Stevens B, Smith CA, Seligman P. Low ferroportin expression in AML is correlated with good risk cytogenetics, improved outcomes and increased sensitivity to chemotherapy. Leuk Res. 2019; 80:1-10. https://doi.org/10.1016/j.leukres.2019.02.011. [PubMed]

15. Kollia P, Stavroyianni N, Stamatopoulos K, Zoi K, Viniou N, Mantzourani M, Noguchi CT, Paterakis G, Abazis D, Pangalos C, Loukopoulos D, Yataganas X. Molecular analysis of transferrin receptor mRNA expression in acute myeloid leukaemia. Br J Haematol. 2001; 115:19-24. https:// doi.org/10.1046/j.1365-2141.2001.03065.x. [PubMed]

16. Lyons RM, Marek BJ, Paley C, Esposito J, McNamara K, Richards PD, DiBella N, Garcia-Manero G. Relation between chelation and clinical outcomes in lower-risk patients with myelodysplastic syndromes: Registry analysis at 5 years. Leuk Res. 2017; 56:88-95. https://doi. org/10.1016/j.leukres.2017.01.033. [PubMed]

17. Scott CS, Ramsden W, Limbert HJ, Master PS, Roberts BE. Membrane transferrin receptor (TfR) and nuclear proliferation-associated Ki-67 expression in hemopoietic malignancies. Leukemia. 1988; 2:438-42. [PubMed] 
18. Buss JL, Greene BT, Turner J, Torti FM, Torti SV. Iron chelators in cancer chemotherapy. Curr Top Med Chem. 2004; 4:1623-35. https://doi.org/10.2174/1568026043387269. [PubMed]

19. Turner J, Koumenis C, Kute TE, Planalp RP, Brechbiel MW, Beardsley D, Cody B, Brown KD, Torti FM, Torti SV. Tachpyridine, a metal chelator, induces G2 cell-cycle arrest, activates checkpoint kinases, and sensitizes cells to ionizing radiation. Blood. 2005; 106:3191-99. https://doi. org/10.1182/blood-2005-03-1263. [PubMed]

20. Messa E, Carturan S, Maffè C, Pautasso M, Bracco E, Roetto A, Messa F, Arruga F, Defilippi I, Rosso V, Zanone C, Rotolo A, Greco E, et al. Deferasirox is a powerful NFkappaB inhibitor in myelodysplastic cells and in leukemia cell lines acting independently from cell iron deprivation by chelation and reactive oxygen species scavenging. Haematologica. 2010; 95:1308-16. https://doi.org/10.3324/ haematol.2009.016824. [PubMed]

21. Calabrese C, Panuzzo C, Stanga S, Andreani G, Ravera S, Maglione A, Pironi L, Petiti J, Shahzad Ali MS, Scaravaglio P, Napoli F, Fava C, De Gobbi M, et al. DeferasiroxDependent Iron Chelation Enhances Mitochondrial Dysfunction and Restores p53 Signaling by Stabilization of p53 Family Members in Leukemic Cells. Int J Mol Sci. 2020; 21:7674. https://doi.org/10.3390/ijms21207674. [PubMed]

22. Zhang Y, Feng X, Zhang J, Chen M, Huang E, Chen X. Iron regulatory protein 2 is a suppressor of mutant p53 in tumorigenesis. Oncogene. 2019; 38:6256-69. https://doi. org/10.1038/s41388-019-0876-5. [PubMed]

23. Vlachodimitropoulou E, Chen YL, Garbowski M, Koonyosying P, Psaila B, Sola-Visner M, Cooper N, Hider R, Porter J. Eltrombopag: a powerful chelator of cellular or extracellular iron(III) alone or combined with a second chelator. Blood. 2017; 130:1923-33. https://doi. org/10.1182/blood-2016-10-740241. [PubMed]

24. Mittelman M, Platzbecker U, Afanasyev B, Grosicki S, Wong RSM, Anagnostopoulos A, Brenner B, Denzlinger C, Rossi G, Nagler A, Garcia-Delgado R, Portella MSO, Zhu Z, Selleslag D. Eltrombopag for advanced myelodysplastic syndromes or acute myeloid leukaemia and severe thrombocytopenia (ASPIRE): a randomised, placebocontrolled, phase 2 trial. Lancet Haematol. 2018; 5:e34-43. https://doi.org/10.1016/S2352-3026(17)30228-4. [PubMed]

25. Frey N, Jang JH, Szer J, Illés Á, Kim HJ, Ram R, Chong $\mathrm{BH}$, Rowe JM, Borisenkova E, Liesveld J, Winer ES, Cherfi A, Aslanis V, et al. Eltrombopag treatment during induction chemotherapy for acute myeloid leukaemia: a randomised, double-blind, phase 2 study. Lancet Haematol. 2019; 6:e122-31. https://doi.org/10.1016/S23523026(18)30231-X. [PubMed]

26. Gorman MF, Ji L, Ko RH, Barnette P, Bostrom B, Hutchinson R, Raetz E, Seibel NL, Twist CJ, Eckroth E, Sposto R, Gaynon PS, Loh ML. Outcome for children treated for relapsed or refractory acute myelogenous leukemia
(rAML): a Therapeutic Advances in Childhood Leukemia (TACL) Consortium study. Pediatr Blood Cancer. 2010; 55:421-29. https://doi.org/10.1002/pbc.22612. [PubMed]

27. Kiem Hao T, Van Ha C, Huu Son N, Nhu Hiep P. Long-term outcome of childhood acute myeloid leukemia: A 10-year retrospective cohort study. Pediatr Rep. 2020; 12:8486. https://doi.org/10.4081/pr.2020.8486. [PubMed]

28. Shen L, Zhou Y, He H, Chen W, Lenahan C, Li X, Deng Y, Shao A, Huang J. Crosstalk between Macrophages, T Cells, and Iron Metabolism in Tumor Microenvironment. Oxid Med Cell Longev. 2021; 2021:8865791. https://doi. org/10.1155/2021/8865791. [PubMed]

29. Torti SV, Torti FM. Iron and cancer: more ore to be mined. Nat Rev Cancer. 2013; 13:342-55. https://doi.org/10.1038/ $\underline{\text { nrc3495. }}$ [PubMed]

30. Forciniti S, Greco L, Grizzi F, Malesci A, Laghi L. Iron Metabolism in Cancer Progression. Int J Mol Sci. 2020; 21:2257. https://doi.org/10.3390/ijms21062257. [PubMed]

31. Amano S, Kaino S, Shinoda S, Harima H, Matsumoto T, Fujisawa K, Takami T, Yamamoto N, Yamasaki T, Sakaida I. Invasion inhibition in pancreatic cancer using the oral iron chelating agent deferasirox. BMC Cancer. 2020; 20:681. https://doi.org/10.1186/s12885-020-07167-8. [PubMed]

32. Argenziano M, Di Paola A, Tortora C, Di Pinto D, Pota E, Di Martino M, Perrotta S, Rossi F, Punzo F. Effects of Iron Chelation in Osteosarcoma. Curr Cancer Drug Targets. 2020 Dec 29. https://doi.org/10.2174/15680096206662012 30090531. [Epub ahead of print]. [PubMed]

33. Negoro E, Yamauchi T, Urasaki Y, Nishi R, Hori H, Ueda T. Characterization of cytarabine-resistant leukemic cell lines established from five different blood cell lineages using gene expression and proteomic analyses. Int J Oncol. 2011; 38:911-19. https://doi.org/10.3892/ijo.2011.933. [PubMed]

34. Tesfay L, Clausen KA, Kim JW, Hegde P, Wang X, Miller LD, Deng Z, Blanchette N, Arvedson T, Miranti CK, Babitt JL, Lin HY, Peehl DM, et al. Hepcidin regulation in prostate and its disruption in prostate cancer. Cancer Res. 2015; 75:2254-63. https://doi.org/10.1158/0008-5472.CAN-142465. [PubMed]

35. Vela D, Vela-Gaxha Z. Differential regulation of hepcidin in cancer and non-cancer tissues and its clinical implications. Exp Mol Med. 2018; 50:e436. https://doi.org/10.1038/ emm.2017.273. [PubMed]

36. Roth M, Will B, Simkin G, Narayanagari S, Barreyro L, Bartholdy B, Tamari R, Mitsiades CS, Verma A, Steidl U. Eltrombopag inhibits the proliferation of leukemia cells via reduction of intracellular iron and induction of differentiation. Blood. 2012; 120:386-94. https://doi. org/10.1182/blood-2011-12-399667. [PubMed]

37. Shi M, Xu F, Yang X, Bai Y, Niu J, Drokow EK, Chen M, Chen Y, Sun K. The synergistic antileukemic effects of eltrombopag and decitabine in myeloid leukemia cells. Cancer Manag Res. 2019; 11:8229-38. https://doi. org/10.2147/CMAR.S213931. [PubMed] 
38. Hancio T, Mazzoccoli L, Guimarães G, Robaina M, Mendonça BDS, Nestal De Moraes G, MonteMor BDCR, Mayumi Gutiyama L, De Carvalho LO, Netto CD, Costa PRR, De Faria FCC, Maia RC. The pterocarpanquinone LQB-118 compound induces apoptosis of cytarabine-resistant acute myeloid leukemia cells. Int J Oncol. 2021; 58:24. https://doi.org/10.3892/ijo.2021.5204. [PubMed]

39. Yao X, Jing X, Guo J, Sun K, Deng Y, Zhang Y, Guo F, Ye Y. Icariin Protects Bone Marrow Mesenchymal Stem Cells Against Iron Overload Induced Dysfunction Through Mitochondrial Fusion and Fission, PI3K/AKT/mTOR and MAPK Pathways. Front Pharmacol. 2019; 10:163. https:// doi.org/10.3389/fphar.2019.00163. [PubMed]

40. Kalota A, Selak MA, Garcia-Cid LA, Carroll M. Eltrombopag modulates reactive oxygen species and decreases acute myeloid leukemia cell survival. PLoS One. 2015; 10:e0126691. https://doi.org/10.1371/journal. pone.0126691. [PubMed]

41. Debebe Z, Ammosova T, Breuer D, Lovejoy DB, Kalinowski DS, Kumar K, Jerebtsova M, Ray P, Kashanchi F, Gordeuk VR, Richardson DR, Nekhai S. Iron chelators of the di-2-pyridylketone thiosemicarbazone and 2-benzoylpyridine thiosemicarbazone series inhibit HIV1 transcription: identification of novel cellular targets-iron, cyclin-dependent kinase (CDK) 2, and CDK9. Mol Pharmacol. 2011; 79:185-96. https://doi.org/10.1124/ mol.110.069062. [PubMed]

42. Debebe Z, Ammosova T, Jerebtsova M, Kurantsin-Mills J, Niu X, Charles S, Richardson DR, Ray PE, Gordeuk VR, Nekhai S. Iron chelators ICL670 and 311 inhibit HIV-1 transcription. Virology. 2007; 367:324-33. https://doi. org/10.1016/j.virol.2007.06.011. [PubMed]
43. Kumari N, Iordanskiy S, Kovalskyy D, Breuer D, Niu $\mathrm{X}$, Lin X, Xu M, Gavrilenko K, Kashanchi F, Dhawan $S$, Nekhai S. Phenyl-1-Pyridin-2yl-ethanone-based iron chelators increase I $\kappa \mathrm{B}-\alpha$ expression, modulate CDK2 and CDK9 activities, and inhibit HIV-1 transcription. Antimicrob Agents Chemother. 2014; 58:6558-71. https:// doi.org/10.1128/AAC.02918-14. [PubMed]

44. Tadesse S, Anshabo AT, Portman N, Lim E, Tilley W, Caldon CE, Wang S. Targeting CDK2 in cancer: challenges and opportunities for therapy. Drug Discov Today. 2020; 25:406-13. https://doi.org/10.1016/j.drudis.2019.12.001. [PubMed]

45. Chen Y, Lu R, Zheng H, Xiao R, Feng J, Wang H, Gao $\mathrm{X}$, Guo L. The NFKB1 polymorphism (rs4648068) is associated with the cell proliferation and motility in gastric cancer. BMC Gastroenterol. 2015; 15:21. https://doi. org/10.1186/s12876-015-0243-0. [PubMed]

46. Karin M, Cao Y, Greten FR, Li ZW. NF-kappaB in cancer: from innocent bystander to major culprit. Nat Rev Cancer. 2002; 2:301-10. https://doi.org/10.1038/nrc780. [PubMed]

47. Basu S, Jalodia K, Ranjan S, Yeh JJ, Peterson RT, Sachidanandan C. Small Molecule Inhibitors of NFkB Reverse Iron Overload and Hepcidin Deregulation in a Zebrafish Model for Hereditary Hemochromatosis Type 3. ACS Chem Biol. 2018; 13:2143-52. https://doi. org/10.1021/acschembio.8b00317. [PubMed] 